\title{
A New Framework for Narcissism in Health Psychology and Psycho-Oncology
}

\author{
Gaia Perego ${ }^{1 *}$ and Valentina E. Di Mattei ${ }^{2,3}$ \\ ${ }^{1}$ Department of Psychology, University of Milano-Bicocca, Milan, Italy, ${ }^{2}$ School of Psychology, Vita-Salute San Raffaele \\ University, Milan, Italy, ${ }^{3}$ Division of Neuroscience, Clinical and Health Psychology Unit, IRCCS San Raffaele Scientific Institute, \\ Milan, Italy
}

Keywords: cancer, humanization of medicine, body image, self-esteem, narcissism

\section{INTRODUCTION}

The extant literature highlights the impact of Narcissistic Personality Disorder (NPD) on health conditions, treatment adherence and interactions with healthcare workers (Quirk et al., 2016; Di Mattei et al., 2018). Specifically, people with NPD show an increased risk for organic disease (Edelstein et al., 2012; Quirk et al., 2016), low treatment compliance (Pontiroli et al., 2007) and a higher use of medical services (Powers et al., 2014). In addition, NPD is associated with harmful health behaviors, such as alcohol and drug use (Luhtanen and Crocker, 2005; MacLaren and Best, 2013; Hill, 2016), risky sexual behavior (Lavan and Johnson, 2002; Martin et al., 2013), and dangerous driving (Hill, 2016). Finally, NPD has been frequently found among people resorting to

OPEN ACCESS

Edited by:

Changiz Mohiyeddini, Oakland University William Beaumont School of Medicine, United States

Reviewed by:

Giulia Fioravanti,

University of Florence, Italy

*Correspondence: Gaia Perego g.perego23@campus.unimib.it

Specialty section: This article was submitted to

Health Psychology, a section of the journal

Frontiers in Psychology

Received: 30 January 2020 Accepted: 07 May 2020 Published: 03 June 2020

Citation:

Perego G and Di Mattei VE (2020) A New Framework for Narcissism in Health Psychology and Psycho-Oncology.

Front. Psychol. 11:1182. doi: 10.3389/fpsyg.2020.01182 cosmetic and plastic surgery (Shridharani et al., 2010; Belli et al., 2013; Agostino et al., 2018).

Nevertheless, considering the high rates found in the general population, NPD has been frequently neglected by psycho-oncology.

Research on NPD is in fact limited by the lack of an exhaustive and univocal conceptualization of the construct (Cain et al., 2008), which is mainly due to differences between phenotypic and taxonomic models and the heterogeneity of the definitions used (Di Pierro and Madeddu, 2018). In fact, the Diagnostic and Statistical Manual of Mental Disorders (DSM) underlined the grandiose and arrogant behavioral manifestations of narcissism, overlooking its vulnerable characteristics, which are most frequently found in clinical practice. The reductionism of the DSM diagnosis led to the underestimation of the prevalence rates of the disorder itself. In addition, the vulnerable manifestations of narcissism received little attention from researchers (Di Pierro and Madeddu, 2020). Moreover, Pincus and Lukowitsky (2010) defined narcissism as the ability of the individual to maintain a relatively positive self-image through self-regulation and interpersonal regulation processes. Narcissism, therefore, can be regarded as a trait present in each individual.

Recently, the definition of DSM-based personality disorder has been revised, questioning its categorical classification and other shortcomings. In particular, NPD has been analyzed focusing on more peculiar themes including vulnerability, grandiosity and self-esteem issues. Indeed, when not rigid and pervasive, narcissism allows the individual to effectively deal with any frustrations by maintaining adequate self-esteem levels and regulating negative emotions (Di Pierro and Madeddu, 2020). These changes enable a new interpretation of several aspects.

\section{SELF-ESTEEM AND CANCER}

Severe medical disease can exacerbate fears of neglect and abandonment, as well as feelings of shame and guilt, leading to behavioral regression (Meyer and Block, 2011) and to the manifestation of narcissistic vulnerabilities. In fact, finding out to be ill often represents a moment of crisis 
with respect to the usual functioning. This is particularly true when referring to a life-threatening diagnosis, such as cancer, which deeply affects the sense of self. Specifically, it affects multiple sources of self-esteem regulation, such as physical appearance, autonomy, independence, power, and social roles.

A peculiar cause of self-esteem impairment is related to alterations in perceived body image (Harter, 1999), as attractiveness is associated with inter-personal success and it is an important determinant of social prestige and acceptance (Marium and Iftikhar, 2014). Body image issues can be detrimental especially for women, as men are more likely to focus their body awareness on functional capabilities, whereas women are more prone to put emphasis on appearance (Halliwell and Dittmar, 2003). Attacks to feminine identity can alter selfesteem, especially in cultures that value traditional gender roles. Compared to men, women seem in fact to be more distressed by cancer-related aesthetic symptoms (Nozawa et al., 2013).

In this regard, a crucial aspect involves the profound impact of oncological treatment. Remarkably, understanding when and how to think psychologically about the patient's situation is beneficial for oncologists, because neglecting mental health compromises patient care (McFarland and Hlubocky, 2019).

For instance, chemotherapy is often associated with cosmetic side effects, including alopecia, paleness, dry skin, and weight loss or gain (Amiel et al., 2009). These adverse reactions can represent for patients a source of distress comparable to the disease itself (Di Mattei et al., 2016, 2017). Notably, the aesthetic consequences of therapies, such as hair loss, can be experienced in terms of a real trauma, especially by the female population (Lemieux et al., 2008), leading to anxiety and depression symptoms (Stafford et al., 2015). In turn, such detrimental effects provoke a significant impairment of selfesteem and perceived body image (Pinar et al., 2012; Di Mattei et al., 2017). In fact, illness often becomes visible with the beginning of treatment, which is experienced as a period of body deterioration (Quintard and Lakdja, 2008) and loss of social and emotional identity (Amiel et al., 2009). Analogously, surgery can deeply affect body image and self-esteem (Callahan, 2005; Melissant et al., 2019), which are negatively associated with a decline in quality of life (Manos et al., 2005). Surgery can damage body integrity with scars or even permanently alter highly visible body parts (e.g., head and neck surgery), functional organs (e.g., colorectal surgery) and symbols of femininity (e.g., breast surgery).

Indeed, the main adverse sequelae spontaneously reported by female cancer patients deal with physical changes, which are described as "painful narcissistic effects" (Amiel et al., 2009). Hair loss and mastectomy are frequently defined as a mutilation (Amiel et al., 2009; Zannini et al., 2012), and they are associated to difficulties in recognizing oneself in the mirror. In this regard, wearing a wig helps women to maintain a sense of identity (Zannini et al., 2012).

Another important aspect concerns social interactions. As hair loss can expose patients to other people judgment, sometimes wearing a wig is a forced choice to hide the disease. In this regard, women report that they wear wigs mainly outside domestic walls because they are embarrassed and they want to avoid pity and compassion from other people (Zannini et al., 2012). Women also declare that people start to look at them differently when they show treatment side effects (Amiel et al., 2009) and they are worried about being deemed unattractive by others (Nozawa et al., 2013).

\section{AESTHETIC CARE INTERVENTIONS}

In this perspective, the introduction of aesthetic care interventions inside hospitals enables a global vision of the patient, not just by "curing" the disease, but also by "taking care" of the person as a whole. These programs can provide female cancer patients with an opportunity to regain a positive contact with their bodies, which have been altered by aggressive therapies, thus reconnecting with their beauty and femininity (Di Mattei et al., 2017). The focus of these interventions is in fact the recovery of adequate self-esteem levels, normally present before cancer diagnosis.

A growing number of studies investigated the efficacy of these programs on women's well-being, both by means of qualitative (Amiel et al., 2009; Zannini et al., 2012) and quantitative data (e.g., Titeca et al., 2007; Quintard and Lakdja, 2008; Park et al., 2015; Richard et al., 2019). The literature indicates that participating in aesthetic care programs could determine an improvement in body image, anxiety, self-esteem, and the quality of social interactions (Quintard and Lakdja, 2008; Richard et al., 2019), thus facilitating a better adjustment to the disease.

\section{HEALTH IN THE MIRROR}

Within this framework, a psychosocial support program named "Health in the Mirror" was developed in Northern Italy. It is an intervention for female cancer patients aimed at helping to manage appearance-related side effects resulting from cancer and its treatment. The program includes an initial psychological assessment and three group sessions that take place on a weekly basis. After an initial make-up and wig tutorial, each patient receives a personalized make-up session and is given the possibility to choose a wig to keep. A photographer captures patients' portraits before and after their personalized treatment. A dermatologist gives a lecture on how to treat the skin and body during cancer treatments. Afterwards, a nutritionist illustrates the guidelines for a healthy diet, suggesting how to counter some of the potential side effects of cancer treatment. Moreover, a fashion stylist offers a customized consultation on the use of colors to match each patient's skin tone. During the last session, a team of psychologists leads a group discussion focusing on patients' cancer experience and their experience of taking part in the program.

Noticeably, a quantitative assessment showed that participating in the Health in the Mirror program fostered a significant reduction in depressive symptoms, anxiety and body image issues, both immediately at the conclusion of the program and 3 months later. Remarkably, self-esteem levels showed an improvement at the 3-months follow-up (Di Mattei et al., 2017). 


\section{DISCUSSION}

Interventions aimed at rebuilding body image following its deterioration seem to favor a normal regulation of self-esteem. This allows the restoration of adequate levels of narcissism. Indeed, being proud and satisfied with oneself and one's own image is not a sign of narcissistic pathology, but rather a form of self-acceptance required for normal development (Thomaes et al., 2010; Lipowska and Lipowski, 2015). For instance, wearing a wig is considered crucial to identity restoration following cancer treatment (Zannini et al., 2012). In addition, photo shooting allows participants to visualize the bodily appearance effects of the beauty care intervention for a second time and to share professionally edited photos, thereby likely fostering increases in self-esteem (Richard et al., 2019).

In general, maintaining a high level of self-esteem predicts better psychological adjustment to cancer and its treatment, in terms of a higher quality of life (Bartoces et al., 2009) and reduced levels of distress, anxiety and depression (Kobayashi et al., 2008; da Mata et al., 2016; Yang et al., 2019). Therefore, in addition to

\section{REFERENCES}

Agostino, A. D., Aportone, A., Monti, M. R., and Lemma, A. (2018). Beauty matters: psychological features of surgical and nonsurgical cosmetic procedures. Psychoanal. Psychol. 35, 244-253. doi: 10.1037/pap0000099

Amiel, P., Dauchy, S., Bodin, J., Cerf, C., Zenasni, F., Pezant, E., et al. (2009). Evaluating beauty care provided by the hospital to women suffering from breast cancer: qualitative aspects. Support. Care Cancer 17, 839-845. doi: 10.1007/s00520-009-0620-8

Bartoces, M. G., Severson, R. K., Rusin, B. A., Schwartz, K. L., Ruterbusch, J. J., and Neale, A. V. (2009). Quality of life and self-esteem of long-term survivors of invasive and noninvasive cervical cancer. J. Womens Health 18, 655-661. doi: 10.1089/jwh.2008.0959

Belli, H., Belli, S., Ural, C., Akbudak, M., Oktay, M. F., Cim, E. F. A., et al. (2013). Psychopathology and psychiatric co-morbidities in patients seeking rhinoplasty for cosmetic reasons. West Indian Med. J. 62, 481-486. doi: 10.7727/wimj.2013.068

Cain, N. M., Pincus, A. L., and Ansell, E. B. (2008). Narcissism at the crossroads: phenotypic description of pathological narcissism across clinical theory, social/personality psychology, and psychiatric diagnosis. Clin. Psychol. Rev. 28, 638-656. doi: 10.1016/j.cpr.2007.09.006

Callahan, C. (2005). Facial disfigurement and sense of self in head and neck cancer. Soc. Work Health Care 40, 73-87. doi: 10.1300/J010v 40n02_05

Cheville, A. L., Alberts, S. R., Rummans, T. A., Basford, G. R., Lapid, M. I., Sloan, J. A., et al. (2015). Improving adherence to cancer treatment by addressing quality of life in patients with advanced gastrointestinal cancers. J. Pain Symptom Manage. 50, 321-327. doi: 10.1016/j.jpainsymman.2015.03.005

da Mata, L. R. F., Chàvez, G. M., Faria, B. S., Antunes, A. C. C., da Silva, M. R., and de Oliveira, P. P. (2016). Self-esteem and distress in patients undergoing cancer surgery: a correlational study. OBJN 15, 664-674. doi: 10.17665/1676-4285.20165398

Di Mattei, V. E., Carnelli, L., Carrara, L., Bernardi, M., Crespi, G., Rancoita, P. M., et al. (2016). Chemotherapy-induced nausea and vomiting in women with gynecological cancer: a preliminary single-center study investigating medical and psychosocial risk factors. Cancer Nurs. 39, E52-E59. doi: 10.1097/NCC.0000000000000342

Di Mattei, V. E., Carnelli, L., Taranto, P., Bernardi, M., Brombin, C., Cugnata, F., et al. (2017). "Health in the Mirror": an unconventional approach to unmet psychological needs in oncology. Front. Psychol. 8, 1633-1640. doi: 10.3389/fpsyg.2017.01633 the best possible medical therapy, the improvement of patients quality of life must be a standard of care in oncology, as it promotes compliance to treatment (Cheville et al., 2015). In this perspective, psychosocial interventions should be combined with standard oncological care (Di Mattei et al., 2018).

In conclusion, as far as narcissistic themes are concerned, it is necessary to go beyond the underestimation often found in oncology and the medical environment. Although many authors agree on the existence of healthy and pathological narcissistic traits, the nature of this distinction is not yet clear. Finally, despite the propensity of psychology to address only profound issues, dealing with apparently trivial themes can enhance patients' self-esteem.

\section{AUTHOR CONTRIBUTIONS}

GP wrote the first draft of the manuscript. VD wrote sections of the manuscript. Both authors contributed to the manuscript revision, read, and approved the submitted version.

Di Mattei, V. E., Mazzetti, M., Taranto, P., Bernardi, M., and Carnelli, L. (2018). Personality disorders: the missing diagnosis in psycho-oncology? Clin. Neuropsychiatry. 15, 258-271.

Di Pierro, R., and Madeddu, F. (2018). Do narcissistic subtypes really exist? An ongoing debate. Clin. Neuropsychiatry. 15, 236-241.

Di Pierro, R., and Madeddu, F. (2020). "Gli orientamenti attuali nella concettualizzazione del narcisismo patologico" in I mille volti di narciso. Fragilità e arroganza tra normalità e patologia, ed F. Madeddu (Milano: Raffaello Cortina Editore), 165-186.

Edelstein, R. S., Newton, N. J., and Stewart, A. J. (2012). Narcissism in midlife: longitudinal changes in and correlates of women's narcissistic personality traits. J. Pers. 80, 1179-1204. doi: 10.1111/j.1467-6494.2011.00755.x

Halliwell, E., and Dittmar, H. (2003). A qualitative investigation of women's and men's body image concerns and their attitudes toward aging. Sex Roles 49, 675-684. doi: 10.1023/B:SERS.0000003137.71080.97

Harter, S. (1999). The Construction of the Self: A Developmental Perspective. New York, NY: Guilford.

Hill, E. M. (2016). The role of narcissism in health-risk and health-protective behaviors. J. Health Psychol. 21, 2021-2032. doi: 10.1177/1359105315569858

Kobayashi, M., Sugimoto, T., Matsuda, A., Matsushima, E., and Kishimoto, S. (2008). Association between self-esteem and depression among patients with head and neck cancer: a pilot study. Head Neck 30, 1303-1309. doi: $10.1002 /$ hed. 20868

Lavan, H., and Johnson, J. G. (2002). The association between axis I and II psychiatric symptoms and high-risk sexual behavior during adolescence. J. Pers. Disord. 16, 73-94. doi: 10.1521/pedi.16.1.73.22559

Lemieux, J., Maunsell, E., and Provencher, L. (2008). Chemotherapyinduced alopecia and effects on quality of life among women with breast cancer: a literature review. Psychooncology 17, 317-328. doi: 10.1002/pon. 1245

Lipowska, M., and Lipowski, M. (2015). Narcissism as a moderator of satisfaction with body image in young women with extreme underweight and obesity. PLoS ONE 10:e0126724. doi: 10.1371/journal.pone.0126724

Luhtanen, R. K., and Crocker, J. (2005). Alcohol use in college students: effects of level of self-esteem, narcissism, and contingencies of self-worth. Psychol. Addict. Behav. 19, 99-103. doi: 10.1037/0893-164X.19.1.99

MacLaren, V. V., and Best, L. A. (2013). Disagreeable narcissism mediates an effect of BAS on addictive behaviors. Pers. Individ. Dif. 55, 101-105. doi: 10.1016/j.paid.2013.02.004

Manos, D., Sebastián, J., Bueno, M. J., Mateos, N., and De la Torre, A. (2005). Body image in relation to self-esteem in a sample of Spanish women with early-stage 
breast cancer. Psicooncología. 2, 103-116. Retrieved from https://revistas.ucm. es/index.php/PSIC/article/view/PSIC0505120103A

Marium, J., and Iftikhar, A. (2014). Adolescent girls are hurt more by the body mass than thin-ideal media images of females. J. Behav. Sci. 24, 29-43. Retrieved from https://search.proquest.com/docview/1645341603?accountid=31754

Martin, A. M., Benotsch, E. G., Perschbacher Lance, S., and Green, M. (2013). Transmission risk behaviors in a subset of HIV-positive individuals: the role of narcissistic personality features. Pers. Individ. Dif. 54, 256-260. doi: $10.1016 /$ j.paid.2012.09.006

McFarland, D. C., and Hlubocky, F. J. (2019). The oncologist as therapist. J. Oncol Pract. 15, 539-546. doi: 10.1200/JOP.19.00237

Melissant, H. C., van Uden-Kraan, C. F., Lissenberg-Witte, B. I., and Verdonckde Leeuw, I. M. (2019). Body changes after cancer: female cancer patients' perceived social support and their perspective on care. Support. Care Cancer 27, 4299-4306. doi: 10.1007/s00520-019-04729-w

Meyer, F., and Block, S. (2011). Personality disorders in the oncology setting. J. Support. Oncol. 9, 44-51. doi: 10.1016/j.suponc.2011. 02.002

Nozawa, K., Shimizu, C., Kakimoto, M., Mizota, Y., Yamamoto, S., Takahashi, Y., et al. (2013). Quantitative assessment of appearance changes and related distress in cancer patients. Psychooncology 22, 2140-2147. doi: 10.1002/pon.3268

Park, H. Y., Kim, J. H., Choi, S., Kang, E., Oh, S., Kim, J. Y., et al. (2015). Psychological effects of a cosmetic education programme in patients with breast cancer. Eur. J. Cancer Care 24, 493-502. doi: 10.1111/ecc. 12290

Pinar, G., Okdem, S., Dogan, N., Buyukgonenc, L., and Ayhan, A. (2012). The effects of hysterectomy on body image, self-esteem, and marital adjustment in Turkish women with gynecologic cancer. Clin. J. Oncol. Nurs. 16, E99-E104. doi: 10.1188/12.CJON.E99-E104

Pincus, A. L., and Lukowitsky, M. R. (2010). Pathological narcissism and narcissistic personality disorder. Annu. Rev. Clin. Psychol. 6, 421-426. doi: 10.1146/annurev.clinpsy.121208.131215

Pontiroli, A. E., Fossati, A., Vedani, P., Fiorilli, M., Folli, F., Paganelli, M., et al. (2007). Post-surgery adherence to scheduled visits and compliance, more than personality disorders, predict outcome of bariatric restrictive surgery in morbidly obese patients. Obes Surg. 17, 1492-1497. doi: 10.1007/s11695-008-9428-8.

Powers, A., Strube, M. J., and Oltmanns, T. F. (2014). Personality pathology and increased use of medical resources in later adulthood. Am. J. Geriatr. Psychiatry 22, 1478-1486. doi: 10.1016/j.jagp.2013.10.009

Quintard, B., and Lakdja, F. (2008). Assessing the effect of beauty treatments on psychological distress, body image, and coping: a longitudinal study of patients undergoing surgical procedures for breast cancer. Psychooncology 17, 1032-1038. doi: 10.1002/pon.1321
Quirk, S. E., Berk, M., Chanen, A. M., Koivumaa-Honkanen, H., BrennanOlsen, S. L., Pasco, J. A., et al. (2016). Population prevalence of personality disorder and associations with physical health comorbidities and health care service utilization: a review. Personal. Disord. 7, 136-146. doi: 10.1037/per00 00148

Richard, A., Harbeck, N., Wuerstlein, R., and Wilhelm, F. H. (2019). Recover your smile: effects of a beauty care intervention on depressive symptoms, quality of life, and self-esteem in patients with early breast cancer. Psychooncology 28, 401-407. doi: 10.1002/pon.4957

Shridharani, S. M., Magarakis, M., Manson, P. N., and Rodriguez, E. D. (2010). Psychology of plastic and reconstructive surgery: a systematic clinical review. Plast. Reconstr. Surg. 126, 2243-2251. doi: 10.1097/PRS.0b013e3181f445ae

Stafford, L., Judd, F., Gibson, P., Komiti, A., Mann, G. B., and Quinn, M. (2015). Anxiety and depression symptoms in the 2 years following diagnosis of breast or gynaecologic cancer: prevalence, course and determinants of outcome. Support. Care Cancer 23, 2215-2224. doi: 10.1007/s00520-014-2571-y

Thomaes, S., Reijntjes, A., Orobio de Castro, B., Bushman, B. J., Poorthuis, A., and Telch, M. J. (2010). I like me if you like me: on the interpersonal modulation and regulation of preadolescents' state self-esteem. Child. Dev. 81, 811-825. doi: $10.1111 / j .1467-8624.2010 .01435 . x$

Titeca, G., Poot, F., Cassart, D., Defays, B., Pirard, D., Comas, M., et al. (2007). Impact of cosmetic care on quality of life in breast cancer patients during chemotherapy and radiotherapy: an initial randomized controlled study. J. Eur. Acad. Dermatol. Venereol. 21, 771-776. doi: 10.1111/j.1468-3083.2006.02080.x.

Yang, Y., Sun, G., Dong, X., Zhang, H., Xing, C., and Liu, Y. (2019). Preoperative anxiety in Chinese colorectal cancer patients: the role of social support, self-esteem and coping styles. J. Psychosom. Res. 121, 81-87. doi: 10.1016/j.jpsychores.2019.02.009

Zannini, L., Verderame, F., Cucchiara, G., Zinna, B., Alba, A., and Ferrara, M. (2012). "My wig has been my journey's companion": perceived effects of an aesthetic care programme for Italian women suffering from chemotherapy-induced alopecia. Eur. J. Cancer Care 21, 650-660. doi: $10.1111 / \mathrm{j} .1365-2354.2012 .01337 . \mathrm{x}$

Conflict of Interest: The authors declare that the research was conducted in the absence of any commercial or financial relationships that could be construed as a potential conflict of interest.

Copyright $\odot 2020$ Perego and Di Mattei. This is an open-access article distributed under the terms of the Creative Commons Attribution License (CC BY). The use, distribution or reproduction in other forums is permitted, provided the original author(s) and the copyright owner(s) are credited and that the original publication in this journal is cited, in accordance with accepted academic practice. No use, distribution or reproduction is permitted which does not comply with these terms. 